\title{
ASPECTOS SEMIÓTICOS DEL DISCURSO DE DENUNCIA SOCIAL EN EL LARGOMETRAJE CARPINTEROS (2017) DEL CINEASTA DOMINICANO JOSÉ MARÍA CABRAL
}

\section{Semiotic aspects of the discourse of social denunciation in the feature film Carpinteros (2017) by the Dominican filmmaker José María Cabral}

\section{Gerardo Roa Ogando}

Doctor en Filosofía del lenguaje con énfasis en Lingüística; investigador de Análisis Crítico del Discurso (ACD) en la Facultad de Humanidades de la Universidad Autónoma de Santo Domingo (UASD) y profesor del Doctorado en Estudios del Español de la Pontificia Universidad Católica Madre y Maestra (PUCMM). gerardoroaogando@gmail.com

Recibido: 23/7/2018 • Aprobado: 23/10/2018

Cómo citar: Roa Ogando, G. (2018). Aspectos semióticos del discurso de denuncia social en el largometraje Carpinteros (2017) del cineasta dominicano José María Cabral. Ciencia y Sociedad, 43(4), 51-66. doi: http://dx.doi.org/10.22206/cys.2018.v43i4.pp51-66

\section{Resumen}

En este artículo se analiza la película dominicana Carpinteros (2017) de José María Cabral desde la perspectiva teórica del signo de Saussure en el Curso de lingüistica general (1945) y desde la teoría del signo de Peirce descrita en su libro La ciencia de la semiótica (1986). Aunque hace más de un siglo que estos autores formularon sus teorías, esta película constituye un macrosigno multimodal que soporta el escrutinio teórico inmanente y trascendente del lenguaje. Por ello, el objetivo fue analizar el discurso ideológico de denuncia social como contenido de las formas semióticas. El procedimiento de análisis ha sido hermenéutico-triangular. Apliqué cuestionarios a tres grupos controles de semiólogos, cineastas y sociólogos en torno a la trilogía: lenguaje, cine y sociedad dominicana. Los resultados muestran correspondencias de estas teorías con la producción cinematográfica analizada. Concluyo proponiendo al lector el estudio de películas, y de otros textos multimodales, a partir de estos autores.

Palabras clave: Análisis del discurso; cine de denuncia social; semiótica; lenguaje; sociedad dominicana.

\begin{abstract}
In this article I analyze the Dominican film Carpinteros (2017) by José María Cabral from the theoretical perspective of the sign of Saussure, in the General Linguistics Course (1945) and from the Peirce sign theory, in his book The Science of Semiotics (1986). Although more than a century ago these authors formulated their theories, this film constitutes a multimodal macrosign that supports the immanent theoretical scrutiny and transcending of language. Therefore, the objective was to analyze the ideological discourse of social denunciation as content of semiotic forms. The analysis procedure has been hermeneutic-triangular. I applied questionnaires to three control groups of semiologists, filmmakers and sociologists around the trilogy: language, cinema and Dominican society. The results show correspondences of these theories with the cinematographic production analyzed. I conclude by proposing to the reader the study of films, and other multimodal texts, from these authors.
\end{abstract}

Keywords: Discourse analysis; cinema of social denunciation; semiotics; language; dominican society. 


\section{Introducción}

La creación artística tiene como finalidad inmanente el goce estético y recreativo de sus destinatarios. A esto se le suma la trascendencia dada por el lenguaje. Esta le admite la propiedad de constituirse en discurso de transmisión de ideología ${ }^{1}$ soterrada. El cine, en sentido extenso, constituye un vehículo de transmisión de sustratos ideológicos diversos, ya sean estos políticos, religiosos, de género, migratorios, deportivos o lingüísticos, etcétera (Althusser, 1974; Bazin, 1985; Van Dijk, 2008, 2005). En este contexto merece mención especial el cine de denuncia social, por su consistencia en la historia de la fílmica a nivel mundial (Corro, Larraín, Alberdi y Van Diest, 2018).

En este sentido, sobresale la película muda, El acorazado de Potemkim (1925) del famoso cineasta y teórico ruso Serguéi M. Eisenstein. Es un largometraje cuyos elementos técnicos y semiológicos fueron utilizados como estrategia de propaganda con la finalidad tangible de legitimar la ideología comunista. Por eso, en su narrativa presenta al trabajador común rompiendo con el yugo de la opresión impuesta por la clase dominante. $\mathrm{Al}$ retratar la explotación de la clase obrera se denuncia de forma reiterada a los opresores.

1. El término ideología fue acuñado por el pensador ilustrado Destutt de Tracy en una colosal obra de cuatro volúmenes a la que tituló Elementos de Ideología (1881). En esta obra concibe la ideología como la ciencia general de las ideas. Posteriormente, Napoleón Bonaparte le dio una connotación peyorativa al término. En el marxismo se desarrolló bastante la concepción de "falsa consciencia" aplicado a las ideologías. Marx y Engels también la definen como aquel sistema de representación del mundo que permite a la clase dominante legitimar su posición privilegiada sobre la clase dominada (Marx y Engels, 1974). En este artículo se emplea el concepto como sistema de ideas del lenguaje que legitiman prácticas sociales. No importa que sean negativas o positivas (Roa, 2018a). Actualmente, desarrollo el programa "Discurso, ideología y cine en la sociedad dominicana”. Se trata de una investigación auspiciada por la Dirección de Investigaciones de la Facultad de Humanidades, Universidad Autónoma de Santo Domingo (UASD).
Una segunda muestra la constituye el filme El gran dictador (1940) de Charles Chaplin. Ésta contiene una fuerte crítica al nacionalsocialismo liderado por Adolf Hitler. En la fílmica se parodia la doble y antagónica personalidad de este dictador, por lo que además de ser un producto cultural recreativo, denuncia la injusticia social antisemita y xenófoba del régimen nazi.

Un tercer ejemplo lo constituye la película $D r$. Strangelove (1964) del cineasta Stanley Kubrick, basada en la Guerra fría estadounidense. En este filme de humor negro se critican implícitamente las estrategias legitimadoras de intromisiones, injerencias y guerras por parte de Estados Unidos de América y sus aliados. En el mismo orden, si alguien pretendiera aproximarse muy de cerca a uno de los procesos de transformaciones políticas en Latinoamérica, como lo fue la Revolución Cubana, la película del director Tomás Gutiérrez Alea, Memorias del subdesarrollo (1968) ofrece al lector una buena oportunidad para alcanzar este objetivo. El personaje principal encarna al ciudadano común, quien tuvo que pasar por un proceso de adaptación, similar al paso de la dictadura al régimen socialista cubano.

A principios del siglo XXI se estrenó la película Hotel Rwanda (2004) una producción cinematográfica que denunció y contextualizó las trágicas secuelas de la segregación colonial y racial en África. Este filme pone de relieve la forma en que un conflicto étnico se convierte en legitimación de una masacre brutal, como fue el caso del genocidio de Ruanda de 1990.

En el contexto dominicano, una parte importante de las producciones cinematográficas han sido vehículo de ideologías de denuncia social. Por supuesto, la dictadura de Rafael Leónidas Trujillo (1930-1961) censuró las películas de corte ideológica, con el alegato de que representaban un peligro para el Estado. Sin embargo, tras la muerte de este déspota dominicano empezaron a 
estrenarse con cierta timidez algunas películas de denuncia social. La silla (1963) considerada por algunos como el primer largometraje dominicano -del cineasta Franklin Domínguez- es un ejemplo de ello. A través de sus escenas se denuncian las atrocidades cometidas por la dictadura. Se revelan los diversos métodos de tortura empleados en las cárceles contra intelectuales opuestos a la ideología de la dictadura instaurada por el presidente Trujillo (Sáez, 1982; Roa, 2017; 2018a).

Más tarde, Agliberto Meléndez estrenó Un pasaje de ida (1988) con la que denuncia los viajes ilegales, así como la complicidad entre las autoridades y los delincuentes comunes. En esta línea se inscriben las dos producciones del cineasta Ángel Muñiz: Nueba Yol 1, por fin llegó Balbuena (1995) y Nueba Yol 3, bajo la nueva ley (1997), la primera de la cual analicé y publiqué en un artículo anterior correspondiente al mismo programa de investigación $\left(2018^{a}\right)^{2}$.

Aunque la dimensión de la denuncia social en el cine ha sido notable (Moreno \& Javier, 2018; Thibaudeau, 2008) gran parte de las investigaciones consultadas se centran en la función recreativa, soslayando las dimensiones socioculturales e ideológicas (Bracco, 2017; Morales, 2017). Sin embargo, los estudios realizados por Félix Manuel Lora Robles (Lora, 2017) y por el investigador de cine Luis Beiro Álvarez (Céspedes, 2018) constituyen antecedentes adecuados. Pero el enfoque empleado por estos y otros investigadores revisados no abordan

2. Los antecedentes históricos de estudios sobre la denuncia social en el contexto cinematográfico se encuentran en los trabajos realizados y publicados por los teóricos del Instituto de Investigación Social (IIS). Dicha escuela surgió en el año 1923 con la finalidad de analizar los discursos propagandísticos para descubrir estrategias de enajenación, confusión y, en definitiva, engaños encubiertos en los productos culturales oficiales, tales como: la prensa, radio, televisión y cine. Sin embargo, la película que he analizado no constituye un producto cultural de ocultación, enajenación o alienación social. Todo lo contrario, Carpinteros es una denuncia social en sí misma. el discurso de denuncia social en las películas como significantes y significados semiolingüísticos. En mi condición de investigador, he publicado dos artículos indexados que abordan variables relativas a los sustratos ideológicos de denuncia social (Roa, 2017; Roa, 2018) por lo que este nuevo aporte se inscribe en esta misma dirección.

La película del cineasta dominicano José María Cabral, cuyo análisis presento en esta entrega, es una fílmica de denuncia social carcelaria. Junto a la película La cárcel de la Victoria, el cuarto hombre (2004) de José Enrique Pintor y junto al filme El rey de Najayo (2012) de Fernando Báez Mella, conforma el subgénero denominado por el crítico de cine, Félix Manuel Lora Robles, como el "cine carcelario dominicano" (Lora, 2017, p. 2). Opino que lo particularmente impresionante en Carpinteros son las estrategias de comunicación semiolingüísticas a través de las cuales se concretiza la denuncia social.

Por eso, las preguntas centrales de esta investigación son ¿en qué consiste el discurso de denuncia social contenido en la película? ¿Cuáles signos de este discurso corresponden a la categoría triádica de Peirce y a la dicotomía de Saussure? ¿Cómo funcionan estos signos en la comunicación interpersonal de la fílmica? ¿Cuáles aspectos semiolingüísticos de las teorías abordadas son aplicables a los estudios de los signos en el presente?

El objetivo general de este estudio ha sido analizar el discurso ideológico de denuncia social ${ }^{3}$ como contenido de las formas semiolingüísticas teorizadas por los pensadores Ferdinand de Saussure y Charles Sanders Peirce. Concretamente, interesa describir la denuncia social para identificar en el entramado cinematográfico los signos, verbales y no verbales, y sus funciones sociales e interpersonales

3. Ni Saussure ni Peirce mencionan el cine dentro de sus ejemplificaciones, debido a que para la época este arte apenas comenzaba a asimilarse. 
desde la perspectiva teórica de estos dos connotados teóricos.

Los resultados arrojados son útiles para cineastas, estudiantes, profesores de cinematografía y de sociología, amén de otras áreas ligadas a las ciencias del lenguaje. Esto es debido a que las teorías del signo en versión de los dos teóricos clásicos abordados, tienen una presencia impresionante en la semiosis de la posmodernidad, al grado de facilitar la comprensión de la naturaleza del cine como dimensión que trasciende la inmanencia propia de las artes. Esta investigación, igualmente, satisface un vacío causado por la casi ausencia de bibliografía con criterio transteórico en el contexto de las producciones culturales.

En definitiva, sostengo que la combinación de signos verbales y no verbales se convierte en una impresionante estrategia con la que se logra, en lo inmanente, la artisticidad del filme y, en lo trascendente, la cruda realidad de las cárceles latinoamericanas que lejos de ser centros correccionales, constituyen espacios de mayor hacinamiento y, en consecuencia, de degradación de los internos (Méndez, 2017).

\section{Aspectos teóricos}

\section{La semiótica de Saussure frente al cine de denuncia social}

Ferdinand de Saussure ${ }^{4}$ es un autor fundamental para comprender el funcionamiento de los signos en el seno de la vida social. Dentro de su alcance entran en cuestión, aunque de soslayo, la

\footnotetext{
4. Ferdinand de Saussure fue un gramático, filólogo y filósofo ginebrino. Con su teoría del signo revolucionó la forma de hacer ciencia dentro del amplio mundo de las ciencias sociales. A partir de la publicación postmorten del Curso de lingüistica general (1916) ha sido considerado por sus principales acólitos como el padre de la lingüística moderna. La versión en la que baso mis opiniones corresponde a la vigésima cuarta edición prologada por Amado Alonso y publicada por la Editorial Losada en Buenos Aires, Argentina, ańo 1945.
}

comprensión de los textos multimodales en los que se representan y se construyen funciones sociales complejas. Este autor concibe el signo como una entidad síquica compuesta por un significado y por un significante acuñada en la mente de los hablantes. Sostiene que: (...) "el lazo que une el significante y el significado es arbitrario, o también, ya que por signo entendemos la totalidad resultante de la asociación de un significante a un significado, podemos decir más sencillamente que el signo lingüístico es arbitrario" (Saussure, 1945, p. 99).

Aunque Saussure reconoce que todo signo contiene esta dualidad, propone la separación entre signos verbales y signos no verbales (Saussure, 1945). Para él sólo los signos verbales corresponden al terreno de lo lingüístico, dentro del amplio mundo de lo que convino en llamar "semiología":

Puede por tanto concebirse una ciencia que estudie la vida de los signos en el seno de la sociedad; formaría una parte de la psicología social y, por consiguiente, de la psicología general; la denominaremos semiología (...) Ella nos enseñaría en qué consisten los signos, qué leyes los rigen... (Saussure, 1945, p. 43).

De ahí en adelante Saussure presenta un conjunto importante de características del signo lingüístico. Dentro de ellas encontramos las formas en que éstos se relacionan entre sí. Por eso, el concepto de oposición y función y los de relaciones sintagmáticas y paradigmáticas entran dentro de las formas solidarias en que las palabras se articulan para producir mensajes, etcétera (Lampis, 2018). Pese a que no dedicó mucho espacio al estudio de los signos no verbales, la separación entre lenguaje, lengua y habla es muy adecuada para el estudio del cine (Saussure, 1945).

Al haber asumido el lenguaje como la capacidad únicamente humana que se encuentra en la tercera circunvolución del lóbulo frontal izquierdo, a través del cual se produce el habla -siguiendo al 
neurofisiólogo francés Paul Broca- muestra reconocimiento a la gran capacidad que poseen los seres humanos para comunicar y para crear mediante formas semióticas, las cuales trascienden las fronteras de lo inmanentemente verbal (Montenegro y Cuevas, 2018; Saussure, 1945).

La afirmación precedente es coherente con la aserción de que la lengua es un sistema de signos similar a la escritura, a la pintura, a las fotografías, a lenguas de seńas, a código morse, a ritos religiosos, danza, teatro, etcétera. Luego Saussure añade que lo verbal constituye lo más importante dentro de todos los sistemas simbólicos. Por eso, entiende que desde un primer momento hay que situarse en el terreno de la lengua y tomarla como norma de los restantes signos (Roa, 2018a). Sin embargo, los avances en estudios lingüísticos con lenguas de señas han mostrado que no son únicamente los idiomas convencionales los modos de representación y expresión del mundo de todos los grupos culturales (Tovar y Gómez, 2018). Con razón, Emile Benveniste prefiere el uso de la expresión "eficaz", en lugar de importante, ya que este término refiere al contexto de uso de un determinado signo (Benveniste, 1985).

Aunque la teoría de este autor constituye un punto de partida de interés para el desarrollo del conocimiento científico sobre los idiomas, resulta insuficiente para el estudio de los aspectos semiolingüísticos en el cine. Sobre todo, porque la inmanencia que Saussure impuso a los estudios de la lengua es aplicable a ciencias exactas, cuyos resultados pretenden ser fieles representaciones de la realidad (Warley, 2018). Se trata de saberes universales que cambian muy poco de un contexto a otro. Pero en la vida real, como en las películas, no encontramos usos lingüísticos ideales, sino formas sociolingüísticas, es decir, hablares normados por los usos culturales, sociales, individuales y contextuales. Con razón se admite que una lengua nadie la habla, sino metáforas y metonimias en cada contexto de uso (Coseriu, 1986; Roa, 2017b).
El lingüista y cineasta francés, Christian Metz ya había impuesto las teorías del signo de Saussure al análisis de películas (Traversa, 2018). Esto supuso enfocarse en sólo los aspectos verbales (las conversaciones) de las fílmicas, soslayando la inmensa dimensión no verbal a través de la cual se transmite una enorme carga semántica a los destinatarios (Metz, 2001; 2002). Es por esto que sus resultados no fueron trascendentes, tampoco aportaron mucho en términos de conocimiento, ya que este tipo de análisis privilegia el rigor del método cuantificable por encima de las actuaciones, creaciones y representaciones socioculturales (Stam, 2001; Meza, 2017).

La crítica que le vino a Metz estuvo dirigida a la cuantificación de los diálogos y sus estructuras sintácticas, morfológicas, lexicales y fonéticas, independiente de las acciones de los personajes en los contextos socioculturales recreados en cada fílmica (Serelle, 2018; Delacruz, 2018). Esto se debió y se debe a que el estudio científico del signo que plantea Saussure es aplicable a lenguas muertas, aunque existan las comunidades de hablantes, como bien lo ilustra el siguiente pasaje: "2. (...) Ya no hablamos las lenguas muertas, pero podemos asimilarnos perfectamente su organismo lingüístico" (Saussure, 1945, p. 42).

$\mathrm{Si}$ algunos aspectos de la teoría del signo de Saussure, en el Curso de lingüistica general, pueden ser aplicados al estudio del cine, no serán mayores a su consideración prospectiva de lo que llamó lingüística del habla y heterogeneidad del lenguaje (Saussure, 1945). Al concebir el habla como el uso concreto que hace un hablante de su conocimiento sobre el sistema (lengua) aproxima el debate en torno a los sujetos y a sus interacciones sociales. Coherente con esta afirmación, Emile Benveniste, en su teoría de la enunciación concibe los usos o hablares como procesos de enunciación, es decir, de discursos (Benveniste, 1985).

La limitación que se advierte desde la perspectiva de estos dos importantes lingüistas es su fiel apego a la 
descripción de la estructura del sistema verbal, en casi detrimento a los signos no verbales (Martínez, 2018). Esa ha sido la tendencia de los estudios del habla. La dialectología, verbigracia, ha centrado su interés en el estudio de los significantes de la cultura, más no en las implicaciones sociales de los significados que emanan de la capacidad humana del lenguaje:

"Al separar la lengua del habla se separa al mismo tiempo: 1) lo que es social de lo que es individual; 2) lo que es esencial de lo que es accesorio y más o menos accidental (...) Mientras que el lenguaje es heterogéneo, la lengua así delimitada es de naturaleza homogénea: es un sistema de signos en el que sólo es esencial la unión del sentido y de la imagen acústica, y donde las dos partes del signo son igualmente psíquicas" (Saussure, 1945, p. 41).

Los aspectos semiológicos de la teoría de este autor aplicable al estudio del cine se presentan en oposición a su concepción de ciencia de la lengua. Su consideración sostiene que la lengua es de naturaleza psíquica. De ese modo excluye lo social por considerar que corresponde al lenguaje, heteróclito. Aunque considera los hechos del lenguaje como accesorios, los tales no pueden ser abordados desde el método positivista trabajado por Saussure (Peronard, 2018).

Con su aceptación de lenguaje como realidad compleja, Saussure admite que no es desde la lengua que se pueden abordar los estudios de las artes y de otras manifestaciones y creaciones del pensamiento; sino desde el "universo de universos comunicativos que, como el cine, resultan de la facultad de simbolización humana" (Roa, 2018a, p. 40). Por ello, los aportes de este autor que permiten un abordaje teórico al estudio del filme tienen como núcleo esta concepción de lenguaje desde una perspectiva transteórica. Sin embargo, sería insuficiente sólo partir de estas ideas tratadas de soslayo por el padre de la lingüística moderna.

\section{La semiología de Peirce frente al cine de denuncia social}

Mientras Saussure privilegia el significante frente al significado, Peirce entiende el signo como "una cosa que se encuentra en lugar de algo con sentido para alguien" (Peirce, 1986, p. 21). De esa forma llama representamen a la primeridad, es decir, a esa cosa que se nos presenta a la vista en lugar de algo. A ese algo o segundidad lo llama significado u objeto del representamen; mientras el tercer elemento es el interpretante, el sujeto capaz de admitirle sentido al signo. A este último también lo ubica en la terceridad (Battista, 2018; Labadie, 2018; Zecchetto, 2013).

Como es evidente, Peirce no establece la separación entre signo verbal y signo no verbal, sino que propone una categoría mucho más abarcadora que la de Saussure a partir de la cual es posible estudiar cualquier sistema simbólico, desde perspectivas inmanentes y trascedentes (Abril, 2008). Para ello, habla del fanerón para referirse a la totalidad de nuestros pensamientos, los cuales pueden ser expresados en forma de lenguaje (Zecchetto, 2013). Asimismo, propone la denominación faneroscopía para designar el estudio lógico del Fanerón o lenguaje, dentro del cual el cine encuentra un espacio idóneo (Roa, 2018, b).

Para Peirce, todo signo contiene los siguientes tres aspectos: el representamen, el objeto y el interpretante. En cuanto a clasificación Peirce propone la siguiente triada: cualisigno-sinsigno-legisigno; ícono-índice-símbolo; decisigno-rema-argumento; inducción-abducción-deducción (Beuchot, 2013).

La primeridad, segundidad y la terceridad corresponden, respectivamente, al representamen, al objeto o significado y al interpretante (Peirce, 1985; Venegas y Acevedo, 2018). Por ejemplo, el cualisigno se refiere al signo adjetivo que expresa cualidades de su objeto representado. Guarda una estrecha relación con el ícono, puesto que es un signo que trata de imitar a su referente, es decir, es idéntico a 
su objeto, como sucede en el caso de la caricatura y de los emoticones que encontramos con frecuencia en las redes sociales (Huerta, 2014).

El sinsigno es un tipo de signo cuyo representamen no corresponde en forma con su objeto. El caso de un croquis, o de un mapa, no tiene mucho que ver con el referente-objeto al cual señala, pero pudiera parecerse en su forma representamen. En tal caso, sería sinsigno, ícono e índice al mismo tiempo. El legisigno, por su parte, coincide con los símbolos y con los argumentos, en tanto la convencionalidad en estos tipos de signos es más notoria que en las anteriores (Roa, 2018 b).

Con frecuencia en una película y en la vida real podemos identificar símbolos del cristianismo, del budismo, de la justicia, de la psicología, de la paz, etcétera. Todos ellos son legisignos porque resultan de una elección más consciente que tácita de un grupo que a través de la argumentación (Inducción, abducción y deducción) llegan a un consenso (Deleuze, Puente y Ires, 2011; Eco, 2013) .

Dada la complejidad que implica la teorización de los signos de Charles Sanders Peirce, parece conveniente aprovechar de sus aportes los conceptos de representamen, objeto e interpretante, puesto que éstos resultan más comprensibles para el análisis de películas. Valga aclarar que el representamen corresponde al significante, en la teoría de Saussure, aunque no circunscrito a lo verbal. Asimismo, el objeto o segundidad corresponde al significado en la versión del teórico europeo. En cuanto a la terceridad o interpretante de Peirce, en Saussure no existe, debido a que este autor deja fuera de su interés de estudio a los sujetos creadores e interpretadores de signos (Coseriu y Azáceta, 1986).

5. Por supuesto, esta forma de abordar el cine no coincide con el canon que estudia la obra fílmica para describir la función de los componentes de la narrativa frente a la emotividad en los televidentes, como defiende el cineasta Gilles Deleuze, etc. Nuestra decisión metodológica resulta, precisamente, de la lectura crítica de los textos fundamentales sobre cine mundial.
Por ejemplo, si de repente alguien observa un relámpago y una secuencia de tres o cuatro truenos bajo un cielo nublado, estamos ante un representamen, justamente lo que nuestros sentidos perciben tal cual, que nos remite a un significado-objeto, lluvia. El observador es el interpretante, para quien el signo adquiere sentido. Para Peirce, tanto los relámpagos como los truenos y el cielo nublado constituyen un signo especial llamado índice, puesto que no guarda relación alguna en su forma con el objeto (lluvia) representado. Pudiera, igualmente, afirmarse que los tres elementos que remiten a lluvia conforman lo que Saussure llama significante. Sin embargo, esta aseveración entraría en pugna con Saussure, para quien el significante sólo es exclusivo de las emisiones verbales.

La denuncia social es sólo uno de los tantos ejemplos de significados, que como en el ejemplo de la lluvia, se enmarañan en las emisiones semio-lingüísticas para alcanzar su intención social. Los demás aspectos de la categoría triádica de Peirce son útiles para describir la multimodalidad semiológica representada en cada toma y secuencia de la película. Esto no resulta extrańo, puesto que un largometraje constituye un texto complejo en el que no solo coexiste lo verbal y lo no verbal, sino que cada una de estas dos dimensiones semiológicas se expresa a través de una diversidad de fusiones entre conversaciones, símbolos, íconos e índices, etcétera, que merece ser vista a partir de una perspectiva transteórica del lenguaje (Abril, 2008; Pérez, 2016).

\section{Aspectos metodológicos}

Esta investigación se inscribe dentro de los estudios culturales. Concretamente corresponde a los estudios transteóricos, multidisciplinares y empíricos, similar al análisis crítico del discurso cinematográfico. Ahora bien, prescinde del rigor de los métodos concebidos de antemano a las realidades ontológicas. Por tanto, el enfoque metodológico aplicado ha sido cualitativo y hermenéutico. Es una investigación 
trascendente -no inmanente- puesto que no se circunscribe al cine por el cine, ni a la semiótica por la semiótica. Tampoco analiza las ideologías por las ideologías, ni el discurso de denuncia según los enfoques lingüísticos tradicionales, sensu stricto.

He seleccionado la película Carpinteros (2017) del dominicano José María Cabral, como corpus de análisis dentro de las 185 películas que desde el año 1922 hasta el año 2018, cuenta el creciente cine dominicano, en parte, debido a la trascendencia que ha tenido en los espacios nacionales e internacionales desde su estreno. Se trata de la primera película dominicana en haberse exhibido en el Festival Internacional de cine de Sundance (2017). En aquel prestigioso escenario tuvo su premier en la categoría World Dramatic Competition. También esta película fue seleccionada en el Festival Internacional de Cine de Guadalajara (2017) obteniendo tres premios: Premio especial FEISAL, Premio a Mejor Actor (Jean Jean) y Premio Especial de Jurado. Igualmente, fue seleccionada en el Miami Film Festival. En todos estos escenarios se destacó la propiedad estética del filme para expresar un discurso de denuncia social mediante un lenguaje semiolingüístico.
En cuanto a técnicas, la hermenéutica ha sido el procedimiento que ha permitido releer las teorías semiológicas que componen el marco teórico de la investigación, con la finalidad de identificar y someter a escrutinio epistémico y dialéctico, aquellos aspectos presentes en la película analizada. Igualmente, la entrevista a sociólogos, semiólogos y a cineastas permitió realizar un análisis desde perspectivas distintas y complementarias a la vez. Por eso, nuestras opiniones son el resultado, en conjunto, de las informaciones obtenidas de nuestras planificadas interacciones con estos grupos de expertos. Igualmente, las reacciones de los estudiantes ante los efectos semiolingüísticos del filme aportaron datos importantes para establecer el nivel de adecuación de las teorías en las producciones semióticas del presente.

En síntesis, el procedimiento de análisis ha sido el siguiente:

1ero. Se describieron los signos representamen (significante) de la película, lo que equivale a exponer la narrativa tal cual se reproduce, identificando diferentes tipos de signos dentro de la categoría de Peirce;

Figura 1. Poster de la película Carpinteros (2017)

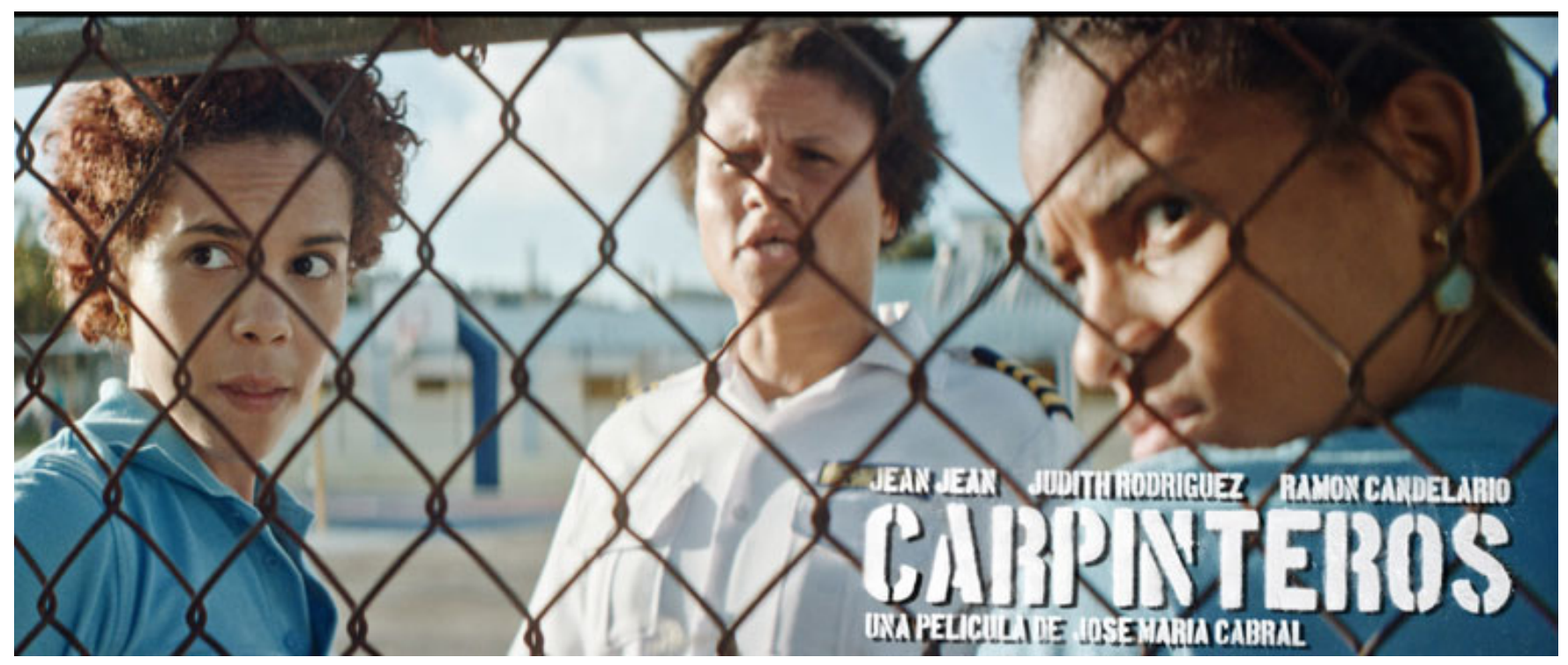

58 | Ciencia y Sociedad 2018; 43(4): 51-66 • Entre líneas 
2do. Se procedió al análisis del significado de la narrativa cinematográfica; esto equivalió a la identificación, enjuiciamiento y contextualización de los sustratos ideológicos del discurso de denuncia social;

3ero. Se obtuvieron los resultados de los especialistas entrevistados y del grupo control de estudiantes;

4to. Se argumentó sobre la forma y función de las teorías que se presentan en la película;

5to. Se verificó el grado en el que las preguntas, objetivos e hipótesis fueron alcanzados.

6to. Se redactó el informe final en base a los hallazgos obtenidos.

\section{Narrativa de la película Carpineros (2017)}

La historia de Julián inicia con la decisión de un juez, quien lo sentenció a pasar un año de prisión preventiva en la cárcel de Najayo (San Cristóbal, República Dominicana). Era un ladrón de motocicleta. Pertenecía a una banda que robaba de forma organizada. Él solo conducía mientras sus compañeros robaban, herían y mataban. No era capaz de quietarle la vida a nadie. Al menos él mismo nunca lo había hecho. Era hijo de un militar corrupto, asesinado mientras se hallaba envuelto en cuestiones de negocios ilícitos. Pretendía continuar con su negocio de tráfico de sustancias prohibidas desde la cárcel, como si delinquir estuviera grabado entre sus genes.

En la cárcel fue recibido por un soldado, quien le entregó un uniforme verde. Luego fue trasladado a la barbería. En aquel lugar fue recortado al raspe. Desde entonces, Julián empezó a sufrir el hacinamiento y el maltrato verbal y físico de los internos más hábiles. Para sobrevivir en una cárcel como esta tendría que demostrar aptitudes y actitudes de supervivencia. Sin embargo, no era de los que tenían mayores posibilidades. Su físico famélico de tez oscura, cabizbajo y de labios gruesos y sangrientos indicaba no poseer la fortaleza física que le permitiría adaptarse al hostil y nuevo entorno.

Tras haber sido objeto de intenso manoteo de bienvenida dispensado por los presos veteranos, Julián conoció a Manaury Encarnación, un interno prepotente que negociaba sustancias prohibidas

Figura 2. Julián preso en la cárcel de Najayo (San Cristóbal, República Dominicana)

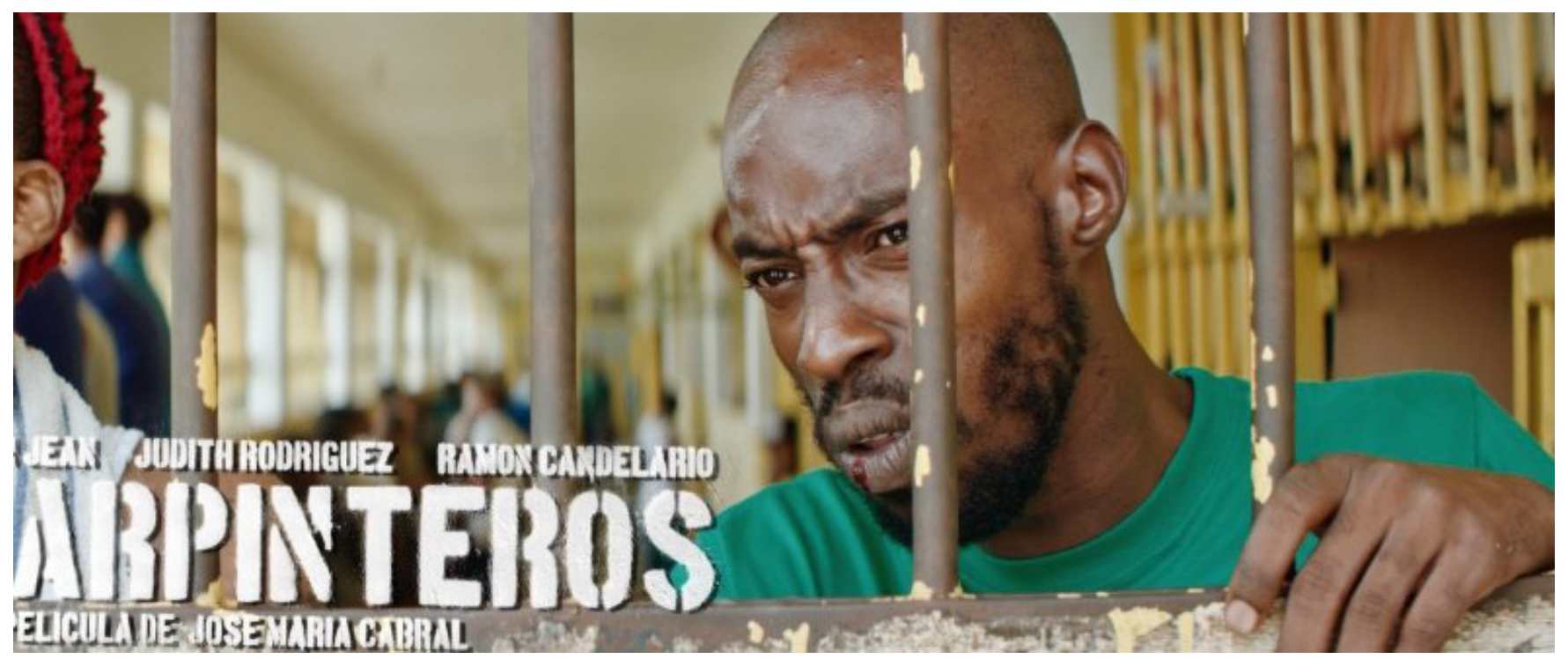


desde y en la cárcel. Manaury le enseñó parte de la vida carcelaria.

Un día Julián observó algunos presos trepados en las rejas de uno de los pabellones y quiso saber de qué se trataba. Al subirse al muro, descubrió la forma en que los presos se enamoraban de las mujeres presas en otro pabellón. Sus relaciones amorosas sólo eran posible a través del lenguaje de señas. De hecho, el título de la película deriva de esta actividad intersubjetiva. Por eso, "carpintear" para ellos, era equivalente a comunicarse a través de señas.

La primera acción que generó el dinamismo de la trama tuvo lugar cuando Manaury descubrió a otro preso carpinteando con Yanelly, su amante. Esta situación generó una aguda disputa, por lo que el personal de seguridad decidió trasladar a Manaury hacia otro pabellón del mismo penal, en el que ya no podía hablar con Yanelly. Ahora Manaury estaba encargado de la cocina.

Dada la imposibilidad de comunicarse con Yanelly, Manaury logra que Julián aprenda el lenguaje de señas para usarlo como mensajero entre ambos. No obstante, Julián y Yanelly se enamoraron intensamente. Al enterarse del idilio de ambos, Manaury se sintió engañado, por lo que desde ese momento no dejó de escatimar esfuerzos para matarlo. Mientras tanto, Julián y Yanelly estaban resueltos a casarse. Era imposible el contacto físico entre ellos. Sus relaciones eróticas las consumaban a través de las prendas íntimas que se enviaban clandestinamente, amén de una fotografía con la que cada uno se autocomplacía.

Cierto día, la administración del penal invitó a algunos internos e internas a recibir entrenamiento como cantantes y como músicos, puesto que a la cárcel visitarían supervisores de la Procuraduría General de la República.

Yanelly tenía dotes para el canto. Su voz era hermosa y sabía hacer buen uso de ella. Por eso fue elegida como vocalista principal junto a dos de sus compañeras de celda. Julián se inscribió, aprovechando la ocasión para tocar la tambora. Una vez en el escenario, Manaury lo identificó, por lo que de inmediato se marchó hacia uno de los pabellones con la finalidad de planear una trampa contra Julián. Se la ingenió para pasar detrás del escenario. Una vez allí, y tras una intrigante conversación, simuló abrazar a Julián al tiempo en que colocó un paquete de drogas en el bolsillo de la camisa de su adversario. Tras haber sido denunciado por Manaury y sus cómplices, Julián quedó ante todos como un delincuente. Sin embargo, explicó valientemente que quien negociaba la droga en grandes cantidades era Manaury.

Como consecuencia Manaury, su ayudante y Julián fueron traslados a la cárcel de la Victoria. En ese lugar el hacinamiento superaba con creces el de la cárcel de Najayo. Desde que Manaury llegó al penal, un grupo de internos se encargó de rasparle la cabeza en contra de su voluntad. La situación no era nada fácil para los nuevos presos. Al ayudante de Manaury lo violaron y lo golpearon brutalmente. A Manaury casi lo mata un preso mucho más agresivo que él. Hasta que de repente aparece en escena una mujer obesa, supuestamente su prima. Ella lo introdujo en su nicho y tras algunas conversaciones le mostró un arma de fuego clandestina. Ambos se dedicaban a la distribución de drogas en y desde la cárcel.

En cuanto a Julián, había sido traslado a otro pabellón de la cárcel. Era inadmisible el que compartiera la misma celda con quien había jurado asesinarlo. Con todo, Manaury se enteró de que si se enfermaba o se accidentaba lo trasladarían para la celda en que se encontraba Julián. Por eso planeó su propio accidente. Calentó una sartén completa de agua y se la vertió en su pierna izquierda. Todo salió como lo había planeado. Ya en la nueva celda, y desde que sintió alivio, empezó a perseguir a Julián.

Por su parte, Yenelly ya había cumplido condena. Se le había notificado su divorcio de un matrimonio anterior. Se encontraba libre y dispuesta a casarse con Julián. Así lo hicieron, acordaron casarse en la cárcel, con la bendición de un pastor 
Figura 3. Manaury mientras persuade a Julián para que le compre drogas

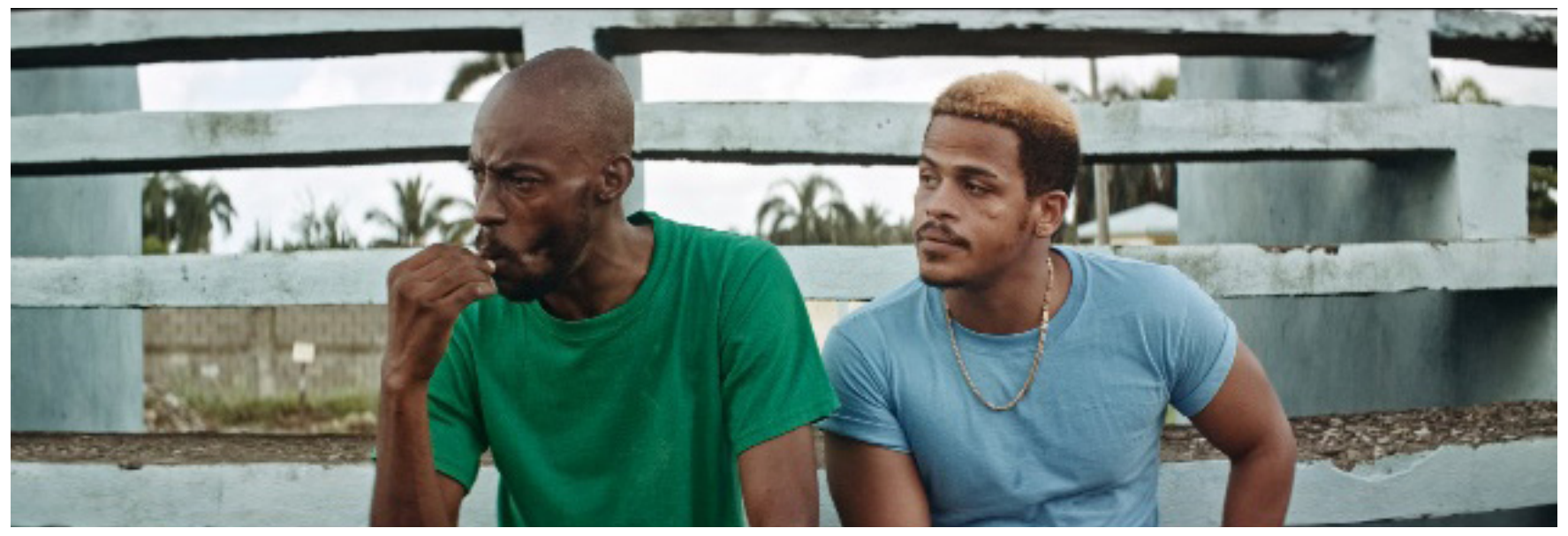

carcelario y de un juez de la oficialía civil local. No habían firmado bien las actas cuando se les aparece Manaury con pistola en manos, mientras profería obscenidades. Ante esto, Julián lo golpeó con una silla plástica, tras lo cual emprendió la huida junto a su reciente esposa. Pero Manaury se levantó y los persiguió hasta alcanzarlos.

La película concluye con por lo menos cinco acontecimientos trascendentes: la matanza entre bandas de presos que se peleaban con armas blancas por el control de los puntos de ventas de drogas; la humareda provocada por las bombas lacrimógenas lanzadas por la policía para disuadir a los belicosos presos; el forcejeo entre Julián y Manaury bajo la humareda; La muerte de Julián a manos de Manaury; la muerte de Manaury a Manos de Yanelly. Finalmente, se observa a la sobreviviente salir caminando de la cárcel en libertad, mientras se despide de los televidentes empleando la lengua de señas.

\section{Aspectos semiológicos y lingüísticos de la película}

Siguiendo a Peirce (1986) y a Saussure (1945) el representamen o significante de la película lo constituye su narrativa audiovisual tal cual acontecen los hechos. El filme constituye en sí mismo un macrosigno de denuncia social, en el que se encuentran entramadas otras frecuencias diversas de signos. Inicia con una secuencia semiológica no verbal acompañada del impactante sonido producto de una potente banda sonora. La toma de un autobús que transporta presos desde la fiscalía hacía la cárcel de Najayo. El semblante de Julián, un personaje con trenzas largas, delgado, alto, negro, labios rotos y de perfil de delincuente común. Aunque se escuchan sonidos en los alrededores, la semiología muda continúa hasta que se escucha decir a la enfermera que atiende a Julián: "Abra la boca”. Luego Julián pasa a ser supervisado por el teniente encargado de la cárcel, el cual le ordena que se desnude. Una vez lo ha hecho le solicita que se baje, le ordena: "bájese", y entonces empieza a revisar sus partes genitales.

La dimensión semiológica más notoria es la común a las cárceles nacionales. Diversidad de presos, algunos con caracteres humildes, mientras a otros se les ve con actitudes violentas. Igualmente, destaca los ritos religiosos que se realizan en el penal. Aparece un pastor predicando y bautizando al estilo protestante.

Otros ritos representamen se relacionan con las celebraciones de grupos que cantan en sus lenguas. Por ejemplo, aparece un grupo de ciudadanos haitianos que cantan en criollo haitiano. Lo extraño a toda esta diversidad intralingüística, es que la película no contenga subtitulación para poder 
comprender las conversaciones en esos sistemas simbólicos distintos al idioma español y al inglés.

Las múltiples escenas en que aparecen los presos agrupados con muy poca ropa debido al intenso calor, constituye un símbolo más de exclusión social y de hacinamiento. Igualmente, las escenas en que aparecen bañándose todos juntos, mientras unos acosan a otros, al caérseles el jabón, es otro microsigno con el que desde la semiología de esta película se denuncia el hacinamiento.

La mayor marca semiológica que presenta esta película es el lenguaje de señas, que más allá de tratarse de gestos paraverbales, constituye representación de las comunidades de sordomudos que se comunican a través de una semiología totalmente distinta a la verbal. De hecho, la artisticidad y la intriga misma de la narrativa se construyen en torno a esta forma de comunicación, como bien reconoce Saussure (1945).

Los aspectos verbales más evidentes en la película corresponden a las emisiones de locuciones interjectivas ${ }^{6}$ obscenas. Las más comunes corresponden al órgano genital femenino. Luego le sigue el uso constante de locuciones interjectivas relacionadas con el sexo oral que emplea el órgano genital masculino, acompańado de la fuerza expresiva, ademanes y otros gestos que transmiten violencia. Todas estas expresiones verbales constituyen el signo representamen, o fotografía, de los sectores excluidos de la sociedad. Por eso son expresadas en un sociolecto de sectores sociales excluidos.

\section{Discusiones en torno al discurso de la denuncia social del filme}

El significado que se expresa en esta película a través de la semiosis verbal y de la no verbal es la denuncia

6. En lingüística, las interjecciones son aquellas expresiones usadas para expresar enfado, enojo, alegría o ira. Algunos ejemplos son: ¡Oh Dios! ¡Sí! ¡Qué bien!, ¡Vete, caramba! etcétera. social. En sentido general, la película pone de relieve una realidad que se vive no sólo en las cárceles, sino también en otros aparatos de estado, como lo muestran los trabajos realizados en los ámbitos locales e internacionales, verbigracia, por Pichardo (2009) y por Almeda y Di Nella (2017). En ambos trabajos se confirma que la representación cinematográfica de la película que aquí analizamos corresponde a la disfuncionalidad de las instituciones públicas, debido a múltiples factores. El principal lo constituye la corrupción institucional. Esta se legitima en complicidad con los demás aparatos de estado al no otorgar, el gobierno, el dinero necesario para educar a los militares del penal y para construir las cárceles necesarias y suficientes, como también corrobora la investigación realizada por el filósofo y sociólogo, Andrés Merejo (Merejo, 2017).

¿Por qué en una cárcel construida para 900 perosonas cohabitan 8,955? ¿No constituye esta representación un sustrato de denuncia social? Múltiples estudios consultados han tomado la sobrepoblación carcelaria como objeto de sus análisis (Casado, 2017; Cobos, 2017; Lora, 2017).

La complicidad y la doble moral son expresadas con auténtica sublimidad en la película. Por ejemplo ¿con la complicidad de quién Manaury vende estupefacientes con tanta naturalidad en la cárcel? ¿Quién le lleva la droga? ¿A quién le paga? En una de las escenas, Julián denuncia que Manaury tiene varios kilos de drogas en el almacén de la cocina, pero cuando el teniente envía a revisar, los soldados sólo le llevan unas pocas bolsitas. ¿No es ésta acaso otra denuncia social enmarañada en semiología de la película? ¿Cómo es posible que en los pabellones de varones conviva una mujer delincuente? ¿Habrá sido este algún error del cineasta, del director o será una fiel representación de la realidad, un signo representamen, en versión de Peirce? ¿Quién les consigue las armas blancas y de fuegos a estos internos? ¿No son acaso éstos íconos, índice y símbolos de la corrupción institucional? ¿No se trata acaso de una película de 
fuertes sustratos ideológicos que como sistema simbólico se convierten en denuncia social?

\section{Conclusiones}

Concluyo afirmando que la artisticidad en la película Carpinteros se construye a partir de la lengua de señas, como símbolos, índice e ícono de la realidad. Esta artisticidad es el resultado del ojo experto de la cámara, posición y movimiento en cada toma y secuencia fílmica. También, concluyo que esta película contiene la denuncia social explícita a lo largo de toda la narrativa como contenido semiolingüístico.

En cuanto a estrategia comunicativa, la subtitulación debió jugar una función importante en todo caso de traducción. Sin embargo, el contexto permitió entender en términos macroestructurales la narrativa, aunque a riesgo de haber cometido algún error de comprensión a nivel microestructural (Van Dijk, 2008).

Respecto a la primera pregunta, sobre la consistencia del discurso de denuncia social de la película, el estudio muestra el hacinamiento, la falta de control, la permisividad y la perversidad, el tráfico de droga, la complicidad entre los delincuentes militares y los delincuentes comunes, etc.

La película completa constituye un macrosigno multimodal, compuesta por signos verbales y no verbales. La teoría del significante de Saussure es aplicable a la textura de las expresiones verbales de la película, los usos del español marginal dominicano y las conversaciones en otras lenguas minoritarias. En cuanto a los aspectos de la teoría de Peirce, el representamen es la cara misma de todos los signos de la película, mientras el significado es la denuncia social como macroestructura semántica que define la narrativa del filme.

La teoría del signo de Peirce es más conveniente para el análisis del cine que las de Saussure, puesto que la cosmovisión del primero es más trascendente y compleja que la del segundo.
Definitivamente, Carpinteros constituye un avance importante en la manera de hacer cine en la República Dominicana. Como arte, logra su fin mediante el juego del lenguaje semiolingüístico; como producto cultural, alcanza su clímax al retratar de forma entretenida una realidad imposible de ocultar con un dedo; en cuanto a vehículo ideológico, todo el que ha visto la película y conoce las cárceles dominicanas descubre en ella ese secreto a voces.

\section{Referencias}

Abril, G. (2008) Análisis critico de textos visuales: mirar lo que nos mira. Madrid: Editorial Síntesis.

Almeda Samaranch, E., \& Di Nella, D. (2017). Mujeres y cárceles en América Latina: perspectivas críticas y feministas. Papers: revista de sociologia, 102(2), 0183-214.

Althusser, L., Gruppi, L., y Paredes, A. (1974). Ideología y aparatos ideológicos de Estado. Barcelona: Gredos.

Battista, E. (2018). Saussure en el discurso del Instituto de Filología de la Universidad de Buenos Aires. Anuario de Letras. Lingüistica y Filología, 5(2), 5-34.

Bazin, A. (1985) ¿Qué es el cine? Barcelona: Gredos.

Benveniste, E. (1985). Problemas de lingüistica general (Vols. I y II). Barcelona. Barcelona: Siglo xxi.

Beuchot, M. (2013). La semiótica: teorías del signo y el lenguaje en la historia. México: Fondo de Cultura Económica.

Bracco, C. (2017). La construcción femenina en los albores del cine egipcio. Imagofagia, (15).

Casado, T. (2017) Las cárceles albergan más de 26 mil internos. República Dominicana. Periódico El Día. Recuperado de http://eldia.com. do/ las-carceles-albergan-mas-de-26-mil-internos/ 
Céspedes, D. (2018). La crítica de cine de Luis Beiro Álvarez: la pantalla al revés. Acento.com. do Recuperado de https://acento.com.do/2018/ opinion/8526378-la-critica-cine-luis-beiro- alvarez-la-pantalla-al-reves/

Cobos López, M. (2017). Principales problemas de los sistemas penitenciarios. Barcelona: Editorial Gredos.

Corro, P., Larraín, C., Alberdi, M., y Van Diest, C. (2018). Teorias del cine documental chileno 19571973. Instituto de Estética. Pontificia Universidad Católica de Chile. Chile: www.tipográfica.cl

Coseriu, E., \& Azáceta, J. M. (1986). Lecciones de lingüistica general. Barcelona: Gredos.

Delacruz, S. L. (2018). El cine traiciona a la pintura: un acercamiento a la teoría fílmica francesa desde André Bazin y Jean Mitry. Fotocinema: revista cientifica de cine y fotografia, (16), 79-101.

Deleuze, G., Puente, S., y Ires, P. (2011). Cine 2: los signos del movimiento y el tiempo. Buenos Aires: Cactus.

Eco, U. (2013). Los límites de la interpretación. Traducción Helena Lozano Miralles. Volumen 258 de Ensayo. Barcelona: DEBOLSILLO.

Huerta, D. G. (2014). Las imágenes macro y los memes de internet: posibilidades de estudio desde las teorías de la comunicación. PAAKAT: Revista de Tecnología y Sociedad,4(7), 11.

Karl, M., y Engels, F. (1974). La ideología alemana. Barcelona: Grijalbo. (1982 a.)-Prefacio para a crítica da economía política. Abril Cultural, Sao Paulo. Sociología. Sao Paulo: Atica. (1982 b.)-

Labadie, J. L. (2018). El lenguaje natural. Iztapalapa, (50), 257-270.

Lampis, M. (2018). Una lectura semiótica del'Cours' en el año de su centenario. Signa: Revista de la Asociación Española de Semiótica, (27), 697-718.
Lora, F. M. "La corrupción institucional y la migración como parte del discurso de denuncia social en el cine de ficción dominicano." Ciencia y Sociedad 42(4), 53-70.

Martínez, I. P. (2018). La concepción de la gramática y el análisis de la oración a partir del Cours de linguistique générale de Ferdinand de Saussure. Revista de Filología de la Universidad de La Laguna, (37), 101-124.

Méndez, W. (2017) Las cárceles explotan por hacinamiento de reclusos. República Dominicana: Periódico Diario Libre, pág. 5.

Merejo, A. (2017) La dominicanidad transida, entre lo virtual y lo real. Santo Domingo: Editorial Santuario.

Metz, C. (2001). El significante imaginario: psicoanálisis y cine. Barcelona: Paidós.

Metz, C. (2002). Ensayos sobre la significación cinematográfica. Barcelona: Paidós.

Meza, M. E. (2017). Apuntes para una reflexión sobre la crítica de cine. Revista Aisthesis (13), 73-78.

Montenegro, G., y Cuevas Tobar, S. (2018). Diferencia en el ser y en la estructura del lenguaje. Diálogo entre Deleuze y Saussure. Paraná, Brasil: Universidad Federal de Integración Latinoamericana (UNILA).

Morales Guzman, J.J. (2015). Elcinecomoactualización del plano de inmanencia en Guilles Deluze. Tesis de maestría. Bogotá: Universidad Sergio Arboleda. Recuperada de https://repository.usergioarboleda.edu.co/bitstream/handle/11232/824/El\%20 cine $\% 20$ como $\% 20$ actualizaci $\%$ C3\%B3n $\% 20$ del $\% 20$ plano $\% 20$ de $\% 20$ imanecia $\% 20$ en $\% 20$ Guilles $\% 20$ Deluze.pdf?sequence $=2 \&$ isAllowed $=y$

Moreno, V., y Javier, S. (2018). Análisis de la representación de la pobreza en el cine ecuatoriano, a través de tres casos de estudio: ratas, ratones y rateros, a tus espaldas y no robarás (Bachelor's thesis, Quito: UCE). 
Peirce, C. S. (1986) La ciencia de la semiótica. Argentina: Editorial Nueva visión.

Pérez, O. (2016). Semiótica: cine y comprensión crítica, cultura de las imágenes, imágenes de la cultura. Santo Domingo: Editora Universitaria de la UASD.

Peronard, M. (2018). El desarrollo de la lingüística y los estudios de cuarto nivel en nuestro país. Calidad en la Educación, (18).

Pichardo, E. (2009) Las cárceles dominicanas todavía son almacenes de presos. República Dominicana. Periódico Hoy, pág. 6.

Roa, G. (2017a). Apuntes para una cronología del cine dominicano. Ciencia y Sociedad, 42(4), 85-90.

Roa, G. (2017b) La lengua, esa gran desconocida. República Dominicana. Fundéu Guzmán Ariza. Recuperado de: http://fundeu.do/la-lengua-esa-gran-desconocida/ Visto: 21 de jul. 2018.

Roa, G. (2018 ${ }^{a}$ Aspectos ideologizantes de las familias representadas en los largometrajes dominicanos Nueba Yol I (1995) de Ángel Muñiz y Yuniol 2 (2007) de Alfonso Rodríguez. Ciencia y Sociedad, 43(2), 35-50.

Roa, G. (2018b) Cosmolingüística y faneroscopía. República Dominicana: Periódico digital ALmomento.net. Recuperado de http://almomento.net/cosmolinguistica-y- faneroscopia/ Visto: 14/06/2018.

Sáez, J. L. (1982) Historia de un sueño importado. República Dominicana: Ediciones Siboney.

Saussure, F. (1945) Curso de lingüistica general. Traducción, prólogo y notas de Amado Alonso. Vigésima cuarta edición. Buenos Aires: Editorial Losada.

Serelle, M. (2018). Crítica cultural da adaptação. Revista Comunicação Midiática, 12(2), p-148.
Stam, R. (2001). Teorias del cine: una introducción. Barcelona: Paidós.

Thibaudeau, P. (2008). El cine de denuncia social en España: El caso de Te doy mis ojos de Icíar Bollaín. Feenstra P, Hermans H. Ejemplar dedicado a: Miradas sobre pasado y presente en el cine español (1990-2005). Foro Hispánico. Revista hispánica de Flandes y Holanda. Amsterdam: Rodopi, 231-249.

Tovar, L. A., \& Gómez, L. L. (2018). La clasificación en la lengua de señas colombiana (LSC). Lenguaje, 46(1), 11-40.

Traversa, O. (2018). Christian Metz y la mediatización. Letra. Imagen. Sonido. Ciudad Mediatizada. (18), 71-87.

Van Dijk, T. (2008). Semántica del discurso e ideología. Discurso \& Sociedad, 2(1), 201-261.

Van Dijk, T. A. (2005). Ideología y análisis del discurso. Utopia y praxis latinoamericana, 10(29), 9-36.

Venegas, C., y Acevedo, C. (2018). Mecanismos de decodificación semiótica utilizados para interpretar los signos en un proceso de comunicación no lingǘstica. Revista Ciencia y Tecnología, 13(2), 21-31.

Warley, J. (2018). Epistemología, argumentación y polifonía (Sobre el" Prólogo a la edición española" del Curso de lingüística general). Anclajes, 8(8).

\section{Películas}

Báez, F. (Director y productor) 2012. El rey de Najayo. Drama carcelario. República Dominicana: David Collado, et al, C x A.

Cabral, J. (Director y productor) 2017. Carpinteros. Drama carcelario. República Dominicana: Tabula Rasa Films.

Chaplin, C. (Director y productor) 1940. El gran dictador. Comedia dramática y satírica. Estados Unidos: Charles Chaplin Film Corporation. 
Domínguez, F. (Director y productor) 1963. La silla. Drama vanguardista. República Dominicana: Domínguez-Johnson Carrau.

Eisenstein, S. (Director). Bliokh, J. (Productor) 1925. El acorazado Potemkin. Drama histórico. Unión soviética: Mosfilm.

George, T. (Director y productor) 2004. Hotel Rwanda. Drama. Reino Unido: Movie.

Gutiérrez, T. (Director y productor) 1968. Memorias del subdesarrollo. Comedia/Drama. Cuba: Film Anffinity.

Kubric, S. (Director y productor) 1964. Dr. Strangelove. Comedia negra. Reino Unido: Hawk Films.
Meléndez, A. (Director y productor) (1988). Un pasaje de ida. Drama. República Dominicana: Cigua Films.

Muñiz, A. (Productor y director). (1995). Nueba Yol 1, por fin llegó Balbuena. Drama cómico. República Dominicana: Cigua Films.

Muñiz, A. (Productor y director). (1997). Nueba Yol 3, bajo la nueva ley. Drama cómico. República Dominicana: Cigua Films.

Pintor, J. (Director y productor) 2004. La cárcel de la Victoria: el cuarto hombre. Drama carcelario. República Dominicana: Hispaniola Pictures.

\section{Datos de filiación}

Gerardo Roa Ogando. Doctor en Filosofía del Lenguaje con énfasis en lingüística; catedrático universitario e investigador de Análisis Crítico del Discurso (ACD) en la Facultad de Humanidades de la Universidad Autónoma de Santo Domingo y profesor del Doctorado en Estudios del Español de la Pontificia Universidad católica Madre y Maestra UCMM. Algunos de sus libros son: La taxonomías del discurso (2016); Estrategias para el desarrollo de la competencia morfosintáctica (2016); Redacción estratégica para el análisis y la producción de discursos académicos (2014); Lingüistica cosmológica (2013). Actualmente realiza una investigación institucional sobre análisis crítico del discurso cinematográfico dominicano en el marco del Doctorado en Filosofía para un Mundo Global de la Universidad del País Vasco. Correo electrónico: gerardoroaogando@gmail.com 